\section{Superb mirror system}

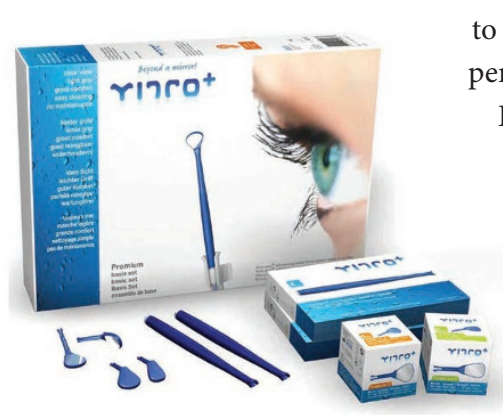

Since every task requires different tools, when it comes to finding a quality dental mirror system, Nuview has the perfect solution.

Boasting a multi-layered coating repellent to grease and contamination, the Yirro-plus PREMIUM and

Yirro-plus COMFORT self-cleaning dental mirror systems offer adjustable airflow for permanent clear vision.

Autoclavable, ultra-reflective and ergonomically beneficial, the mirror is available as both an automatic switched system (PREMIUM) or as a manual device (COMFORT).

Whatever the choice, every start set provides

eight lightweight handles and 12 detachable mirror heads - in two different sizes - ready for immediate use.

Developed by dental experts, the Yirro-plus meets all relevant guidelines, requires no maintenance and is designed to meet every practice's mirror system needs.

For more information on how this innovative dental mirror system could benefit your practice, contact Nuview today.

Call Nuview on 01453872266 or visit www.nuview.co.

\title{
Everything for precise, effective cleaning
}

At the BDIA Dental Showcase 2016, delegates were able to discover that Tandex has everything your patients could ever need for precise, effective cleaning. Tandex makes high-quality brushes and other adjunctive products. The team demonstrated the comprehensive range available, including the SOLO interspace brush, plus the FLEXI and PROXI interdental brushes, which can both be used safely by patients with a variety of needs. Ergonomically designed and able to access the hard-to-reach areas, the brushes come in different sizes to suit all mouths.
Tandex believes that optimal oral hygiene can be achieved with the right products. To complement the brush range there is Tandex

GEL, which is non-abrasive and contains $0.2 \%$ sodium fluoride, plus a mouthwash for complete care. A clean and healthy mouth inbetween appointments will help your patients to avoid invasive treatment as well as smile with confidence. If you didn't manage to catch up with

Tandex at ExCeL London, visit the website to find out what its products can offer your patients. www.tandex.dk

\section{New luting brochure available}

GC's new luting brochure is designed to help clinicians choose the optimal GC luting cement for each indication.

Today, more than ever, clinicians are spoilt for choice when planning and delivering indirect restorations. Therefore, because no two patients are alike, it is important to follow a holistic approach in treatment planning, considering the choice of indirect restoration and type of preparation best suited to each individual's needs. An important part of this process is choosing the right luting cement. The key question is: which is the optimal luting material to protect the tooth structure and prosthetic restoration?

GC's new luting brochure provides the answers to all the key questions, enabling clinicians to select the most appropriate solution from their high five for each individual clinical situation. As well as covering topics ranging from when to cement and when to bond, it also details all the main features and benefits, and clinical applications of their complete range of luting materials including their latest innovation G-CEM LinkForce.

Contact GC UK Ltd on 01908218999 or visit www.gceurope.com.

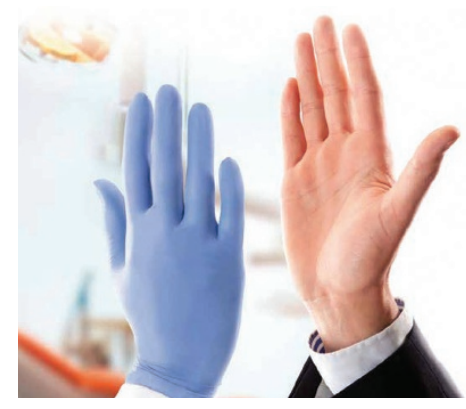

\section{Driving success with award-winning solutions}

For professionals looking to enhance their practice while making life easier, Carestream Dental offered award-winning solutions at this year's BDIA Dental Showcase.

The CS R4+ practice management software proved popular as always, offering the benefits of real-time data collection for highly accurate practice analysis.

Information was available on Springboard V2 - due to be released in January 2017 - which has already received overwhelmingly positive feedback from the profession with $86 \%$ of dentists asked stating that the new features will make their job easier. The new DEPPA integration was also praised by the profession $-100 \%$ of dentists asked believed this would save them significant clinical time.

Another key solution was the innovative CS 3600 intraoral scanner and Carestream Dental was delighted to confirm three Clinical Leads - Dr Charl Du Toit, Dr Jan Einfeldt and Dr Jaswinder Gill. The CS 3600 is the latest model based on the hugely successful CS 3500 intraoral scanner, which came out on top for both trueness and precision when compared to three other scanners.

The CS 8100 3D was another awardwinning product on display, having been shown as the leading solution for accuracy and consistency when digitalising models.

To enhance your practice the easy way, contact Carestream Dental today.

www.carestreamdental.co.uk 